\title{
Decreased Expression of Aquaporins in Otitis Media: What About Chronic Otitis Media?
}

\author{
Shin Hye $\mathrm{Kim}^{1}$ (D) $\cdot$ Moo Kyun Park ${ }^{2}$ (D) \\ ${ }^{1}$ Department of Otorhinolaryngology-Head and Neck Surgery, Haeundae Paik Hospital, Inje University College of Medicine, Busan; \\ ${ }^{2}$ Department of Otorhinolaryngology-Head and Neck Surgery, Seoul National University Hospital, Seoul National University College of Medicine,
}

Seoul, Korea

Water and electrolyte channel proteins in the mucous membrane of the middle ear are involved in the accumulation and reduction of fluid in the middle ear. The aquaporin (AQP) water channels are integral membrane proteins and members of a larger family of major intrinsic proteins that form pores in biological cell membranes. AQPs facilitate the transport of water between cells, while preventing the passage of ions and other solutes [1]. The expression levels of individual AQPs vary among species and animal models, and 11 AQP members (AQP 1-11) are expressed in the mammalian middle ear and eustachian tube.

Fluid accumulation in the middle ear and eustachian tube, which is a pathological feature of all types of otitis media, causes edema that in turn leads to tissue inflammation, and the likely involvement of various AQPs. Because AQPs regulate water levels in the middle ear, decreased expression of these proteins would likely result in excessive accumulation of fluid in the middle ear cavity, thus causing persistent otorrhea. A recent investigation of the expression levels and role of AQPs in patients with chronic otitis media (COM) with otorrhea, published in Clinical and Experimental Otorhinolaryngology by Kim et al. [2], found that the mRNAs of AQPs 1-6, 8, and 10 were expressed in inflammatory tissue obtained from patients with $\mathrm{COM}$, with or without otorrhea. Moreover, AQP 4 and 6 mRNA levels were significantly lower in the otorrhea group in this study.

Various pathophysiological findings have been reported in patients with $\mathrm{COM}$, including biofilm formation in the middle ear, increased levels of the chemokine interleukin (IL)- 8 in middle ear effusion, increased levels of the inflammatory cytokines tumor necrosis factor- $\alpha$, IL- 6 , IL-1 $\beta$, and interferon- $\gamma$ in the middle ear mucosa, and bony destruction [3-6]. The study by Kim et al. [2] suggested that decreased expression of AQP mRNAs is associated with otorrhea in patients with COM.

To date, a total of 15 studies have assessed AQP expression in the middle ear and eustachian tube in rat, mouse, and guinea pig models, and in human patients. The findings of these studies suggest that AQP expression varies according to species and tissue type. Moreover, the expression levels of AQPs differ according to the presence or absence of inflammation. Although AQP 4 mRNA expression has been observed in normal human middle ear epithelium, AQP 4 expression may be associated with middle ear and eustachian tube pathology; a previous study found that AQP 4 expression in the middle ear may be regulated by the condition of the middle ear [7]. Few studies have assessed AQP 6 expression in the middle ear and eustachian tube.

In contrast to their earlier finding that the expression of AQPs was increased in patients with otitis media [8], reported that AQP 4 and 6 mRNA levels were significantly lower in COM patients with otorrhea in the study by Kim et al. [2] Both increases and decreases in AQP expression may negatively affect fluid regulation in the middle ear. Additional studies are needed to clarify the cause and effect relationships between AQP expression and middle ear and eustachian tube pathologies including otitis media and COM.

\section{CONFLICT OF INTEREST}

No potential conflict of interest relevant to this article was reported.

\section{ORCID}

Shin Hye Kim https://orcid.org/0000-0001-9050-0831

Moo Kyun Park https://orcid.org/0000-0002-3621-4524

Copyright (C) 2019 by Korean Society of Otorhinolaryngology-Head and Neck Surgery.

This is an open-access article distributed under the terms of the Creative Commons Attribution Non-Commercial License (http://creativecommons.org/licenses/by-nc/4.0)

which permits unrestricted non-commercial use, distribution, and reproduction in any medium, provided the original work is properly cited. 


\section{REFERENCES}

1. Agre P. The aquaporin water channels. Proc Am Thorac Soc. 2006 Mar;3(1):5-13.

2. Kim JH, Kim SS, Kim YI, Jung SY, Kim SH, Yeo SG. Decreased aquaporin 4 and 6 mRNAs in patients with chronic otitis media with otorrhea. Clin Exp Otorhinolaryngol. 2019 Aug;12(3):267-72.

3. KhosraviY, Ling LC, Loke MF, Shailendra S, Prepageran N, Vadivelu J. Determination of the biofilm formation capacity of bacterial pathogens associated with otorhinolaryngologic diseases in the Malaysian population. Eur Arch Otorhinolaryngol. 2014 May;271(5):1227-33.

4. Elmorsy S, Shabana YK, Raouf AA, Naggar ME, Bedir T, Taher S, et al. The role of IL-8 in different types of otitis media and bacteriological correlation. J Int Adv Otol. 2010 May;6(2):269-73.

5. Si Y, Zhang ZG, Chen SJ, Zheng YQ, Chen YB, Liu Y, et al. AttenuatedTLRs in middle ear mucosa contributes to susceptibility of chron- ic suppurative otitis media. Hum Immunol. 2014 Aug;75(8):771-6.

6. Yorgancilar E, Yildirim M, Gun R, Bakir S, Tekin R, Gocmez C, et al. Complications of chronic suppurative otitis media: a retrospective review. Eur Arch Otorhinolaryngol. 2013 Jan;270(1):69-76.

7. Morris LM, DeGagne JM, Kempton JB, Hausman F, Trune DR. Mouse middle ear ion homeostasis channels and intercellular junctions. PLoS One. 2012;7(6):e39004.

8. Jung SY, Kim SS, Kim YI, Kim HS, Kim SH, Yeo SG. Expression of aquaporins mRNAs in patients with otitis media. Acta Otolaryngol. 2018 Aug;138(8):701-7.
Received May 16, 2019

Accepted June 18, 2019 